\title{
Does luck exclude knowledge or certainty?
}

\author{
Asbjørn Steglich-Petersen \\ Aarhus University \\ Penultimate draft. Forthcoming in Synthese.
}

\begin{abstract}
A popular account of luck, with a firm basis in common sense, holds that a necessary condition for an event to be lucky, is that it was suitably improbable. It has recently been proposed that this improbability condition is best understood in epistemic terms. Two different versions of this proposal have been advanced. According to my own proposal (Steglich-Petersen 2010), whether an event is lucky for some agent depends on whether the agent was in a position to know that the event would occur. And according to Stoutenburg (2015; forthcoming), whether an event is lucky for an agent depends on whether the event was guaranteed or certain to occur in light of the agent's evidence. In this paper, I argue that we should prefer the account in terms of knowledge over that in terms of evidential certainty.
\end{abstract}

Keywords: Luck. Probability theory of luck. Knowledge. Epistemic probability.

\section{Introduction}

Winning the lottery is lucky. Being struck by a falling piece of satellite debris is unlucky. What makes these incidents matters of luck, good or bad? Partly it has to do with their significance for the person who wins or is struck. It is good to win the lottery, bad to be struck by satellite debris. But many things that are of significance are not a matter of luck. ${ }^{1}$ It is good for me to have two legs, bad for me to be stuffed after dinner, but hardly a matter of luck. Some further condition is needed. In particular, it seems that only events that are somehow improbable or fluky can be lucky. Prominent proposals for this additional condition include modal fragility (e.g. Pritchard 2005, 2014; Levy 2011), low objective probability (e.g. Rescher 1995; Baumann 2012; McKinnon 2013), and lack of control over the lucky event (e.g. Coffman 2009; Riggs 2009). But all of these accounts face compelling counterexamples (e.g. Lackey 2006; 2008; Hales 2016). ${ }^{2}$

A promising recent alternative instead proposes to understand the necessary improbability or flukiness in epistemic terms. According to this position, what matters is not the lucky event's objectively probability or modal status, but rather the lucky agent's epistemic position with respect to the relevant event. Two different versions of the epistemic

\footnotetext{
${ }^{1}$ For discussion of this 'significance condition' on luck, see e.g. Ballantyne (2012).

${ }^{2}$ For a helpful recent review of the debate, see Broncano-Berrocal (2018). For a general discussion of the methodology driving this and similar debates, see Praëm and Steglich-Petersen (2015).
} 
account have been proposed. According to my own proposal (Steglich-Petersen 2010), whether an event is lucky for some agent depends on whether the agent was in a position to know that the event would occur. To be more precise, I have proposed the following necessary condition on luck (Steglich-Petersen 2010: 369):

The knowledge condition: $\mathrm{S}$ is lucky with respect to $\mathrm{E}$ at $\mathrm{t}$ only if, just before $\mathrm{t}, \mathrm{S}$ was not in a position to know that $\mathrm{E}$ would occur at $\mathrm{t}$.

Recently, Gregory Stoutenburg (2015; forthcoming) has proposed an alternative epistemic account. According to this account, only events that were not guaranteed or certain to occur given an agent's evidence, can be lucky for that agent. More precisely, Stoutenburg proposes the following (forthcoming: 7 ): ${ }^{3}$

The epistemic probability condition: $\mathrm{S}$ is lucky with respect to $\mathrm{E}$ only if $\mathrm{E}$ was improbable to some degree for $\mathrm{S}$ (where $\mathrm{E}$ was improbable to some degree for $\mathrm{S}$ if and only if immediately prior to E's occurring, S's evidence did not guarantee that E would occur).

Stoutenburg further specifies that 'epistemic guarantee' should be understood as an evidential probability of 1, i.e. evidential certainty. For ease of presentation, I will refer to the accounts that include these respective necessary conditions on luck as the "knowledge account' and the 'certainty account'.

It should be noted that both of these proposed necessary conditions are intended as minimal conditions for an event to be a matter of luck at all. Luck comes in degrees, so, holding other conditions fixed, the farther an event is from being known or certain for an agent, the luckier it is, on the respective accounts. Events must satisfy the epistemic conditions in order to be lucky to some degree for an agent.

As Stoutenburg (2015; forthcoming) and I (Steglich-Petersen 2010) have argued in detail, the epistemic accounts stand at a significant advantage over non-epistemic ones over a wide range of cases. Objective probability accounts fail because even predetermined events can be lucky for an agent (Pritchard 2005: 126-27). Epistemic accounts can handle

\footnotetext{
${ }^{3}$ Stoutenburg's statement of the condition has been altered slightly for ease of presentation. He first states the embedded necessary and sufficient conditions for an event to be improbable, and then states that satisfying this is necessary for an event to be lucky. Here, I state both in a single condition.
} 
predetermined events, since such events need not be known or probable in light of one's evidence (Steglich-Petersen 2010). Modal accounts fail because even modally robust events can be lucky (Lackey 2006; 2008). But again, epistemic accounts can handle modally robust events, since such events need not be known or probable in light of one's evidence (Steglich-Petersen 2010). And as argued by Stoutenburg (forthcoming), epistemic accounts can handle all of Hales' (2016) recent counterexamples involving lucky necessities (more on these below), skilful luck, ${ }^{4}$ and diachronic luck. ${ }^{5}$ In light of this, the epistemic accounts must be considered as serious contenders for the correct theory of luck. ${ }^{6}$

My focus in the following, however, is not on the merits of the epistemic accounts compared to the non-epistemic accounts. As noted, both I (Steglich-Petersen 2010) and Stoutenburg (2015; forthcoming) have discussed these in detail. Rather, my focus for discussion in the following is which of the proposed epistemic accounts is more plausible.

Stoutenburg only provides some brief considerations in support of preferring his certainty account over the knowledge account. In his (2015), Stoutenburg points out that the plausibility of the knowledge account depends on one's account of knowledge; that is, there are ways of understanding knowledge that would make the knowledge account of luck implausible. That is of course correct. While there is more than one understanding of knowledge that would render the knowledge account of luck plausible, it is obviously also

\footnotetext{
${ }^{4}$ Hales' cases of skilful luck are those where theories of luck allegedly misclassify events as lucky, when they are really attributable to skill. For example, Ty Cobb, the best hitter in baseball history, averaged .367 over his career, but it was nevertheless improbable for any particular at-bat that he would get a hit. All theories of luck, including the epistemic one, would thus classify his hits as lucky, which Hales claims to be implausible. However, as Stoutenburg convincingly argues, this is in fact the right classification. Luck is a matter of degree, and at least some degree of luck was involved every time Cobb got a hit. Skill can reduce the degree of luck, but does not necessarily eliminate it (Forthcoming: 10-12).

${ }^{5}$ Hales' cases of diachronic luck show that our attributions of luck sometimes depend on whether the event is considered in isolation or in relation to other events. For example, the record-breaking shot in a series of basketball free-throws seems luckier than the previous shots in the series. But all of the shots were equally likely to go in when seen in isolation, which seems to force probabilistic accounts, including the epistemic one, to count all of the shots as equally lucky. Stoutenburg argues that this can be explained in terms of the significance condition, since the record-breaking shot was of greater significance to the shooter (Forthcoming: 12-13). As noted by an anonymous reviewer, it might be objected that all of the shots were equally necessary for breaking the record. But this does not prevent that more is at stake with the last shot (or the farther into the series one gets), since it is rare to get a single shot which by itself can make the difference between breaking the record or not.

${ }^{6}$ That is not to say that there are no remaining problems for the account. An anonymous reviewer objects that on the epistemic account, and perhaps especially the knowledge account, everything will be a matter of luck to creatures that are not capable of having knowledge. The force of this objection depends on (i) what creatures we are willing to attribute luck to, and (ii) what creatures we are willing to attribute knowledge to. Since we routinely attribute knowledge to a wide range of animals, and there seems to be a lower bound to the organisms that we attribute luck to (can snails be lucky? What about bacteria?), there is reason to expect a reasonable overlap between (i) and (ii).
} 
possible to imagine some that would not. But that is not in itself a problem, as long as the knowledge account is plausible given the most plausible understandings of knowledge.

Later, in his (forthcoming: 5-7), Stoutenburg focuses on my suggestion that the knowledge account of luck might be combined with an interest-relative account of knowledge, according to which standards for knowledge depend in part on the epistemic agent's practical situation (Steglich-Petersen 2010: 369). This suggestion is made in the context of considering whether the knowledge account is too weak, in the sense of counting too many events as lucky, but it is merely offered as a possible response, and is in any case not essential to the knowledge account of luck. So Stoutenburg's argument against combining the knowledge account of luck with an interest-relative account of knowledge should not carry much weight when deciding between the competing epistemic accounts of luck. It is therefore still an open question which of the epistemic accounts of luck is preferable.

In the remaining part of this article, I argue that the knowledge account should be preferred to the certainty account. In Section 2, I show that Hales' (2016) counterexamples involving lucky necessities, which Stoutenburg (forthcoming) argues leave both epistemic accounts of luck intact, in fact only leave the knowledge account intact. In Section 3, I present two further counterexamples to Stoutenburg's certainty account, which the knowledge account also survives, and present a general diagnosis. In short, the problem with the certainty account is that it focuses on just a single luck-inducing epistemic limitation, namely an evidential probability short of 1 . But there are other epistemic limitations that could also make an event lucky for an agent, even if the event was certain for that agent. Only a condition on luck in terms of knowledge can take all of the epistemic limitations relevant to luck into account.

\section{Lucky necessities}

As mentioned above, Hales (2016) presents a series of counterexamples, that he takes to collectively demonstrate the falsity of every extant theory of luck. In one group of the examples, Hales describes events that appear to be either metaphysically or logically necessary, but nevertheless lucky. If we accept that the examples do indeed describe metaphysically or logically necessary lucky events, modal accounts of luck are in trouble, since such events do not fail to occur in nearby worlds - or, indeed, in any world. And depending on one's theory of objective probability, some or all of the examples seem to 
threaten probability accounts of luck as well. At least logical necessities have an objective probability of 1 , so if there are logically necessary lucky events, a low probability cannot be a necessary condition for an event to be lucky. It will be useful to consider two such examples (Hales 2016: 495-6):

\author{
The Logical Bandit \\ The logical bandit points a gun at you and tells you that unless you correctly answer a logic puzzle, \\ he's going to steal your wallet. He gives you this poser:
}

Suppose you go to a diner where the cook is famous for pancakes. Actually, he is famous for burning $50 \%$ of the pancake-sides he cooks, and cooking the other $50 \%$ perfectly. The statistics: One third of his pancakes are golden on both sides; one third are black on both sides; and the remaining third are golden on one side and black on the other. You order a pancake. When it comes, the side you can see is golden. What is the chance that the other side is golden?

You are horrible at this sort of thing, and are completely flummoxed by the gun, the puzzle, and the whole situation. You make a wild guess and say "it's $2 / 3$." The logical bandit, who could tell you were just guessing, smiles ruefully and replies, "you're lucky the correct answer is indeed 2/3," and vanishes into the night. Mathematical facts are of course necessarily true, and so it is a matter of logical necessity that the right answer to the pancake puzzle is $2 / 3$.

\title{
Fermat
}

The Pythagorean Theorem is $\mathrm{A}^{2}+\mathrm{B}^{2}=\mathrm{C}^{2}$. In 1637 Pierre de Fermat wondered if this formula would work for powers other than 2 . He decided that the answer was no, and that $\mathrm{A}^{\mathrm{N}}+\mathrm{B}^{\mathrm{N}}=$ $\mathrm{C}^{\mathrm{N}}$ has no solutions for $\mathrm{N}$ in the positive integers greater than 2 . He famously wrote in the margins of his copy of Diophantus's Arithmetica that he had discovered a marvelous proof of this theorem, which the margins were too small to contain. Generations of mathematicians attempted to prove or falsify Fermat's last theorem, without success, until Andrew Wiles succeeded in 1995. Since it took 358 years for anyone to prove the theorem, and then only by using branches of mathematics that didn't exist in Fermat's day, no one believes that Fermat himself had really discovered a sound proof. Instead his unknown "proof" is assumed to be partial or flawed, as were all the other attempts for over three centuries. Fermat was lucky that his last theorem was true, despite his flawed proof, because it secured his mathematical immortality. Needless to say, Fermat's last theorem is necessarily true.

If the protagonist in The Logical Bandit is lucky that the correct answer is $2 / 3$, and Fermat is lucky that his last theorem is true, then both modal accounts and objective probability accounts are in trouble, since these facts are necessary, and have an objective probability of 1. ${ }^{7}$ However, as Stoutenburg (forthcoming) points out, the epistemic accounts of luck may

\footnotetext{
${ }^{7}$ There may be room for doubt about Hales' verdicts. In particular, as Hales himself notes (2016: 497), while both cases clearly involve luck, some may find it less obvious what exactly the luck pertains to. An alternative interpretation of The Logical Bandit is that the protagonist is lucky that he guessed correctly, which was neither necessary nor particularly probable, since he could easily have guessed something else. Likewise, while it may be necessary that Fermat's last theorem is true, it was neither necessary nor particularly probable that Fermat would believe that it is. However, Hales provides reasons for doubting that this 'paraphrasing strategy' will be successful (2016: 497). As an anonymous reviewer points out, there may be further reason to doubt the
} 
fare better. In fact, Stoutenburg claims, both the certainty account and the knowledge account survive the counterexamples. Here is what he says on behalf of the certainty account (forthcoming: 10):

\begin{abstract}
Consider Hales's logical bandit case. [The certainty account] handles this case with ease. You do not understand the puzzle, so the details of the puzzle that entail the correct answer are not included in your evidence. If the probability of the answer being $2 / 3$ had been 1.0 on your evidence, you would have been in a position to know that $2 / 3$ was the answer, and consequently not lucky to answer correctly. You clearly were not in a position to know the answer, since you had to guess. So, the probability condition is satisfied.
\end{abstract}

If the certainty account is to survive the counterexample, Stoutenburg must demonstrate that the probability of the correct answer being $2 / 3$ is not 1 in light of the protagonist's evidence. But on the face of it, this probability is 1 , since it is entailed by the details of the puzzle. Any proposition that is entailed by a body of evidence has a probability of 1 in light of that evidence. So on the face of it, the certainty account fails.

Two ways of resisting this conclusion can be discerned in the above quoted passage. The first is to deny that the details of the puzzle are included in the protagonist's evidence, on the grounds that he did not understand the puzzle. But in Hales' original example, it seems that the protagonist does understand the details of the puzzle, and there is no reason why he should not. Indeed, the details of the puzzle are relatively simple. What the protagonist struggles with is drawing the right inference from the details, not the details themselves. However, if there is any doubt about how to best interpret Hales' example, we may simply amend it to include that the protagonist does understand the details, without thereby affecting the intuition that he was lucky that the answer was $2 / 3$. So this way of resisting the conclusion seems to fail.

The second way Stoutenburg attempts to resist the above conclusion is by relying on an intuition about what the protagonist knows. If the probability of the answer being $2 / 3$ had been 1.0 on the protagonist's evidence, Stoutenburg argues, he would have been in a position to know the answer; so, since he clearly was not in a position to know the answer (after all, he had to guess), the probability of the answer being $2 / 3$ on his evidence could not be 1 . This argument is clearly valid. But its main premise is false. It is not the case that if the likelihood of a proposition $\mathrm{p}$ on one's evidence is 1 , then one is in a position to know p. Further conditions are required for being in a position to know a proposition. The most

Fermat case, since Fermat may have been reliable in coming up with true theorems, even when he wasn't able to construct a proof. However, this source of doubt could plausibly be remedied by stipulating that Fermat was not reliable at such non-rigorous conjecturing. 
obvious condition is that one is able to correctly assess how probable $\mathrm{p}$ is in light of one's evidence. That is clearly what is missing in The Logical Bandit case, where the protagonist knows the details of the puzzle, but can't determine what they support or entail. It doesn't help here to adopt an infallibilist condition on knowledge. Even if being in a position to know $\mathrm{p}$ requires that the probability of $\mathrm{p}$ on one's evidence is 1 , one cannot reason from the protagonist not being in a position to know $\mathrm{p}$, to the evidential probability of $\mathrm{p}$ on his evidence being less than 1, since, again, failure to be in a position to know may be due to other factors, such as not being able to assess the evidence. The only account of knowledge that would allow the inference from an absence of knowledge to an evidential probability of less than one, is an account that not only, as traditional infallibilists do, makes a probability of 1 necessary for being in a position to know, but also makes such a probability sufficient for being in a position to know. ${ }^{8}$ But that is clearly implausible. One can have evidence that entails a proposition without being able to realise that it does. In such situations, one is clearly not in a position to know the proposition. If one were to adopt belief in the proposition on the basis of one's evidence under such circumstances, the belief would not count as knowledge.

Despite Stoutenburg's arguments, it thus remains plausible that the probability of the correct answer being 2/3 was 1 in light of the protagonist's evidence, in which case the certainty account fails. The knowledge account, on the other hand, has an easier response. Even if the correct answer being $2 / 3$ had a probability of 1 , the protagonist was not in a position to know this, since he wasn't able to deduce this answer from his evidence. So it is compatible with the knowledge account that he was lucky that the correct answer was $2 / 3$.

The above considerations against the certainty account and in favour of the knowledge account applies mutatis mutandis to the Fermat counterexample, too. It was lucky for Fermat that his last theorem was true. But this was also certain on his evidence. Fermat presumably knew enough mathematics to make it the case that there was a possible proof from his mathematical evidence, i.e. his knowledge, to the theorem, but in that case, the probability of the theorem on his evidence was 1, even if Fermat wasn't able to construct this proof. If so, the certainty account of luck fails. However, although it was certain on Fermat's evidence that the theorem was true, he was not in a position to know this, since

\footnotetext{
8 Stoutenberg appears to be accepting such a strong version of infallibilism in the main text on page 7 in his (forthcoming); however, in the accompanying footnote 12, he appears to instead endorse the more traditional and less demanding version of infallibilism that makes evidential certainty a mere necessary condition for being in a position to know. In any case, his account of luck requires the stronger version in order to survive Hales' counterexamples, which should be seen as a significant drawback.
} 
he wasn't able to construct the proof. So the knowledge account of luck delivers the correct verdict.

\section{Further counterexamples to the certainty account}

Hales' counterexamples provide compelling reason to prefer the knowledge account over the certainty account. But the discussion of these examples also points to further cases that can help decide between these two accounts. What we are looking for are cases of lucky events that were certain in light of the lucky agent's evidence, but that the agent was nevertheless not in a position to know would occur. One class of such cases are those in which, as in Hales' examples, the agent isn't able to draw the right inference from his evidence. But there is at least one further class of such cases. These involve higher-order defeat, i.e. defeat that does not affect the evidential probability of the proposition one might adopt belief in, but rather bears on one's ability to properly assess the evidence one has for that proposition. Consider the following variation of The Logical Bandit:

\footnotetext{
The Logical Bandit with Higher-Order Defeat

The logical bandit points a gun at you and tells you that unless you correctly answer a logic puzzle within two minutes, he's going to steal your wallet. He then gives you the details of the puzzle [the same as in Hales' original version]. You are usually pretty good at logic puzzles, and after a bit of thinking, you reach the correct answer of $2 / 3$. However, the bandit then tells you that he slipped a powerful reason-distorting drug into your coffee just before pointing his gun at you. Reasonably, this convinces you that you have most likely made a mistake, even though in this instance, you did not in fact make a mistake. You consequently come to regard it as unlikely that the answer is $2 / 3$. However, the clock is ticking, and you might as well venture some answer. You can't think of a better one, so you take a chance and tell the bandit your original answer. The logical bandit smiles ruefully and replies, "you're lucky the correct answer is indeed 2/3," and vanishes into the night.
}

It seems clear that insofar as it was lucky for the protagonist that the correct answer was $2 / 3$ in the original Logical Bandit case, we should deem it lucky in the present case as well. In the original case, the answer was pure guesswork. The protagonist had no idea what the correct result was, and just picked a random answer. In the present case, the protagonist arrives at the correct result by reasoning in the right way from the details of the puzzle. But he then becomes rationally convinced that this result is most likely false, and only sticks with the answer for want of time and a better one. In his evidential situation, this answer isn't much better than any other, since he has compelling reason to believe that whatever answer he will come up with will be wrong. So from his own perspective, $2 / 3$ is as much guesswork as any other. 
The question is, then, whether was it evidentially certain for him that the answer was $2 / 3$. In the current literature on higher-order defeat, the majority view is that if it was certain in light of his first-order evidence, i.e. the details of the puzzle, then it continues to be certain after adding the higher-order evidence. Indeed, one of the features of higherorder defeat that makes it puzzling and interesting, is that it seems capable of defeating rational belief in a proposition without affecting the probability of that proposition. ${ }^{9}$ In the present case, it is especially clear that it doesn't. That the correct answer to the puzzle is $2 / 3$ is entailed by the details of the puzzle whether or not the protagonist, or anyone else for that matter, is drugged. What the main camps in the debate over higher-order defeat differ on is how we should respond to higher-order defeat, not whether it affects the probability of first-order propositions.

This leads us to the next relevant question, namely whether the protagonist in the above example was in a position to know that the answer was $2 / 3$. Here, opinions are likely to be somewhat more divided. Conciliationists think that higher-order evidence can undermine the rationality of a belief, with the result that one should give up the belief, or at least become less confident, even when the first-order evidence strongly supports, or, as in the present case, entails the proposition in question. ${ }^{10}$ Steadfasters, on the other hand, think that one can sometimes be rational in continuing to believe a proposition in the face of higher-order evidence. ${ }^{11}$ Obviously, I cannot hope to adjudicate between conciliationist and steadfast approaches here, but at least the following can be noted: while there is near universal agreement in the literature on higher-order defeat that the protagonist's evidence in the above example made it certain for him that the correct answer was $2 / 3$, there is some disagreement over whether he was in a position to know it. In order to yield the right intuition in the above case, the knowledge account of luck must side with those that think that higher-order evidence can defeat knowledge. Still, this makes the prospects of the knowledge account significantly brighter than those of the certainty account.

There is a further class of cases that may help decide between the competing epistemic accounts of luck. These do not include any particular luck-inducing epistemic

\footnotetext{
${ }^{9}$ For discussions making this clear, see e.g. Christensen (2010) and DiPaolo (forthcoming). For my own preferred account of higher-order defeat, see Rasmussen et al. (2018), Skipper \& Steglich-Petersen (forthcoming a), and Steglich-Petersen (forthcoming). For a recent collection of essays on higher-order evidence, see Skipper \& Steglich-Petersen (forthcoming b).

${ }^{10}$ For defences of conciliationism about higher-order evidence, see e.g. Feldman (2005), Christensen (2010), and Horowitz (2014).

${ }^{11}$ For steadfast positions on higher-order evidence, see e.g. Kelly (2010), Lasonen-Aarnio (2014), and Titelbaum (2015).
} 
shortcoming, but instead highlight that it takes more epistemic factors than evidential certainty to rule out luck. Evidential certainty cannot do this on its own. Consider the following case, inspired by those described by Martin Smith in his (2010) and (2016).

\begin{abstract}
The background colour
Martin has set up his computer such that, whenever he turns it on, a random number generator determines the background colour on his display. For one out of a million possible values, the background will be red. For the remaining 999.999, it will be blue. Martin turns on his computer, and then leaves the room before seeing the background colour. A few minutes later, Martin's housemate Bruce enters the room and sees that the background colour is blue.
\end{abstract}

As Smith notes, in cases like this, it seems that while Bruce would be justified in believing that the background colour is blue, Martin would not. Martin would of course be justified in believing it to be very likely that the colour is blue, but not justified in outright believing this. It also seems that while Bruce is in a position to know that the background colour is blue (after all, he's just seen that it is), Martin is not. Again, Martin is in a position to know that the background is very likely to be blue. But he is not in a position to know that it is. As Smith notes, what's especially interesting about such cases, is that these verdicts about the relative epistemic positions of Martin and Bruce hold even if we suppose that the probability of the background being blue is greater on Martin's evidence than on Bruce's. For example, we can suppose, plausibly, that the various error possibilities not ruled out by his evidence (hallucination, tricky lighting, or what have you) makes the probability of the background being blue given Bruce’s visual experience lower than .999999. Still, he seems to be in a better position to know that the screen is blue, than Martin.

It is a contentious issue what in particular it is about Bruce's epistemic situation that makes him better placed to know than Martin. Smith (2010; 2016) suggests that what accounts for Bruce's better position is that his belief enjoys normic support, which means that it would require explanation if Bruce's belief were false, but not if Martin's belief were false. Another possible diagnosis is that while Bruce's belief is sensitive, Martin's isn't, where a person's belief that $\mathrm{p}$ is sensitive if and only if that person would not believe $\mathrm{p}$ if $\mathrm{p}$ were false (Dretske 1971; DeRose 1996). If the background colour hadn't been blue, Martin would still have believed this, since he was basing his belief on probabilities only. But one needn't be committed to any of these particular diagnoses to agree with the above verdicts. What is clear is that Bruce is in a superior epistemic position in virtue of having something more than merely probabilistic evidence, which is all that Martin has. 
Turn now to consider luck. Suppose that both Martin and Bruce in light of their respective evidence form the belief that the background is blue. And indeed, it is blue. Are any of them lucky to have formed a true belief? Bruce's true belief does not seem lucky. He is looking at the display, and sees that the background is blue. If it hadn't been blue, he wouldn't have believed it. Very plausibly, Bruce thus knows that it is blue. It would seriously stretch our concept of luck to deem his true belief lucky. Martin, on the other hand, seems to enjoy at least some degree of luck in his true belief, even if it was statistically very unlikely to be false. Martin would not be justified in believing outright that the screen is blue. He does not know that it is blue, only that it is very likely to be blue. And if it hadn't been blue, he would still have believed it to be blue. So it does seem at least slightly lucky that he has ended up believing the truth. At the very least, the following seems clear: Martin is luckier than Bruce is, in ending up with a true belief. ${ }^{12}$

How do these verdicts help decide between the two epistemic accounts of luck? If we think that it isn't lucky for Bruce to have ended up believing the truth, he is a counterexample to the sufficiency of the certainty account, since it isn't certain in light of his evidence that the background is blue (assuming that it was also of positive significance for Bruce to have a true belief). But Bruce is no counterexample to the knowledge account, since he is in a position to know that the background is blue. That Martin is at least slightly lucky to have a true belief is not in itself a counterexample to the certainty account, since it wasn't certain for him that the background is true. But Martin being luckier than Bruce does speak against the certainty account, because on this account, the degree of luck attaching to an event is a function of the evidential probability (keeping the significance fixed). The certainty account thus predicts the opposite, namely that Bruce is luckier than Martin. The knowledge account, on the other hand, has the right prediction: since Bruce is in a position to know that the background is blue, and Martin isn't in a position to know this, despite it being more probable on his evidence, it follows on the knowledge account that Martin is luckier than Bruce.

We have now considered two further classes of cases, in addition to the cases described by Hales, that seem to favour the knowledge account over the certainty account. This allows a more general diagnosis. The cases display how three different kinds of factors that can stand in the way of knowledge, apart from a low evidential probability, can make

\footnotetext{
12 While these verdicts about luck clearly rest on intuitions and not arguments, they are widely accepted in the literature on epistemic luck. See e.g. Pritchard (2005).
} 
an event lucky for an agent. In Hales' cases, it was the agent's inability to process the evidence. In the additional cases, it was higher-order defeat and an absence of certain nonprobabilistic factors necessary for knowledge. This shows than an epistemic account of luck that relies on evidential probability alone cannot account for all of the ways in which epistemic limitations can affect luck. Knowledge is a state that excludes a number of different epistemic limitations, so an account of luck in terms of knowledge is better placed to take the limitations relevant to luck into account.

\section{References}

Ballantyne, Nathan (2012). Luck and interests. Synthese 185 (3): 319-334.

Baumann, Peter (2014). No luck with knowledge? On a dogma of epistemology. Philosophy and Phenomenological Research 89 (3): 523-551.

Broncano-Berrocal, Fernando (2016). Luck. Internet Encyclopedia of Philosophy.

Coffman, E. J. (2009). Does luck exclude control? Australasian Journal of Philosophy 87 (3): 499-504.

Christensen, David (2010). Higher-order evidence. Philosophy and Phenomenological Research 81 (1): 185-215.

DeRose, Keith (1996). Knowledge, assertion, and lotteries. Australasian Journal of Philosophy 74: 568-80.

DiPaolo, Joshua (forthcoming). Higher-order defeat is object-independent. Pacific Philosophical Quarterly.

Dretske, Fred (1970). Epistemic operators. Journal of Philosophy 67: 1007-23.

Feldman, Richard (2005). Respecting the evidence. Philosophical Perspectives 19 (1): 95-119.

Hales, Steven D. (2016). Why every theory of luck is wrong. Noûs 50 (3): 490-508.

Horowitz, Sophie (2014). Epistemic akrasia. Noûs 48 (4): 718-744.

Kelly, Thomas (2010). Peer disagreement and higher order evidence. In Alvin I. Goldman \& Dennis Whitcomb (eds.), Social Epistemology: Essential Readings. Oxford University Press. pp. 183-217.

Lackey, Jennifer (2006). Pritchard's epistemic luck. The Philosophical Quarterly 56: 284-89.

Lackey, Jennifer (2008). What luck is not. Australasian Journal of Philosophy 86 (2): 255 - 267.

Lasonen-Aarnio, Maria (2014). Higher-order evidence and the limits of defeat. Philosophy and Phenomenological Research 88 (2): 314-345.

Levy, Neil (2011). Hard Luck: How Luck Undermines Free Will and Moral Responsibility. Oxford University Press.

McKinnon, Rachel (2013). Getting luck properly under control. Metaphilosophy 44 (4): 496-511.

Praëm, Sara K. \& Asbjørn Steglich-Petersen (2015). Philosophical thought experiments as heuristics for theory discovery. Synthese 192: 2827-42.

Pritchard, Duncan (2005). Epistemic Luck. Oxford University Press.

Pritchard, Duncan (2014). The modal account of luck. Metaphilosophy 45 (4-5): 594-619.

Rasmussen, Mattias S., Asbjørn Steglich-Petersen \& Jens Christian Bjerring (2018). A higher-order approach to disagreement. Episteme 15: 80-100.

Rescher, Nicholas (1995). Luck: The Brilliant Randomness of Everyday Life. Farrar, Straus and Giroux.

Riggs, Wayne (2009). Luck, knowledge, and control. In D. Pritchard, A. Haddock \& A. 
Millar (eds.), Epistemic V alue. Oxford University Press. pp. 204-221.

Skipper, Mattias \& Asbjørn Steglich-Petersen (forthcoming a). Group disagreement: a belief aggregation perspective. Synthese.

Skipper, Mattias \& Asbjørn Steglich-Petersen (forthcoming b). Higher-Order Evidence: New Essays. Oxford University Press.

Smith, Martin (2016). Between Probability and Certainty: What Justifies Belief. Oxford University Press.

Smith, Martin (2010). What else justification could be. Noûs 44 (1): 10 - 31.

Steglich-Petersen, Asbjørn (forthcoming). Higher-order defeat and doxastic resilience. In M. Skipper \& A. Steglich-Petersen (eds.), Higher-Order Evidence: New Essays. Oxford University Press.

Steglich-Petersen, Asbjørn (2010). Luck as an epistemic notion. Synthese 176 (3): 361-377. Stoutenburg, Gregory (2015). The epistemic analysis of luck. Episteme 12 (3): 319-334.

Stoutenburg, Gregory (forthcoming). In defense of an epistemic probability account of luck. Synthese.

Titelbaum, Michael (2015). Rationality's fixed point (or: in defense of right reason). Oxford Studies in Epistemology 5: 253-294. 